\title{
Amino-Claisen Rearrangement of Vinyl Propargylamines and Pyrindane Synthesis from a Divinyl Ketone
}

\author{
KAREN BERG-NIELSEN and LARS SKATTEBøL
}

Department of Chemistry, University of Oslo, Oslo 3, Norway

The amino-Claisen rearrangement of 3-(2propylamino)-2-cyclopenten-1-one, 3-(2-propynylamino)-2-cyclohexen-1-one, and 3-(2-propynylamino)indenone proceeded with electrocyclic ring closure to 6,7-dihydro-1-pyrindin-5one, 5,6,7,8-tetrahydroquinolin-5-one, and $5 H$. indeno $[1,2-b]$ pyridin-5-one, respectively. On the other hand, 3-amino-2-(2-propynyl)-2-cyclohexen-1-one isomerized to 4,5,6,7-tetrahydro-2methylindol-4-one. 1-(1-Cyclopentenyl)-2-propen-1-one heated with benzylamine afforded 1-benzyl-octahydro-1H-1-pyrindin-4-one.

In contrast to phenyl propargyl ether $N$. propargylaniline resists the aromatic aminoClaisen rearrangement when heated to $160^{\circ} \mathrm{C}$; mainly decomposition to aniline occurs. ${ }^{1}$ On the other hand, $N$-propargyl-1- and 2naphthylamine at $250{ }^{\circ} \mathrm{C}$ are converted to a mixture of tetrahydrobenzoquinolines and benzoquinolines, ${ }^{2}$ and with copper(0) and copper(I) chloride as catalysts, 2,2-dimethyl-1,2-dihydroquinoline was obtained from 3anilino-3-methyl-1-butyne at room temperature. ${ }^{3,4}$ Claisen rearrangement with subsequent electrocyclic ring closure of vinylpropargylamines therefore might be a possible route to fused dihydropyridines.

The desired vinylpropargylamines were obtained from the reaction of propargylamine with cyclopentane-1,3-dione and with cyclohexane-1,3-dione which afforded 3-(2-propynylamino)-2-cyclopenten-1-one (1) and 3-(2-propynylamino)-2-cyclohexen-1-one (2) in 76 and $74 \%$ yields, respectively. Moreover, 3-(2propynylamino)indenone (3) was obtained from the reaction of propargylamine with indane-1,3dione. On the other hand, 3-amino-2-cyclohex-

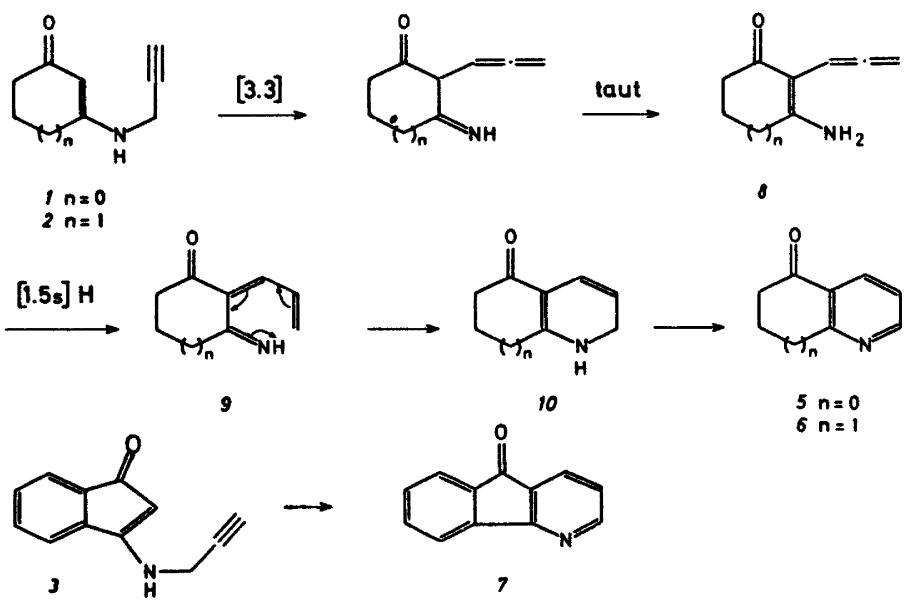

Scheme 1.

Acta Chem. Scand. B 32 (1978) No. 8 
en-1-one reacted with propargyl bromide to 3-amino-2-(2-propynyl)-2-cyclohexen-1-one (4) in $59 \%$ yield.

In hot nitrobenzene compounds 1,2 and 3 underwent amino-Claisen rearrangement and ring closure to 6,7-dihydro-1-pyrindin-5-one (5), 5,6,7,8-tetrahydroquinolin-5-one (6), and $5 H$-indeno[1,2-b]pyridin-5-one (7) in 68,50 , and $40 \%$ yields, respectively. Analogous reactions in benzonitrile at $240{ }^{\circ} \mathrm{C}$ gave the same products in only $10-15 \%$ yields. Other solvents and the use of copper(0) and copper(I) chloride as catalysts resulted in even poorer yields of the desired products. An interpretation of this thermal rearrangement is depicted in Scheme 1.

An amino-Claisen reaction followed by tautomerization provides the allenic enamine 8 . This rearranges by a $[1,5]$ sigmatropic hydrogen shift to the intermediate 9 which undergoes ring closure to the intermediate 10; dehydrogenation yields the observed products 5,6 , and 7. The intermediate 10 is most probably unstable at high temperatures since it could not be isolated from any of the reaction mixtures. When nitrobenzene is used as a solvent it also acts as a dehydrogenating reagent in the last step and the yields are four to seven times higher than in other solvents. Aniline is formed as a byproduct; the reaction was followed by gas chromatography which revealed an increase of the aniline concentration during the reaction.

Base-catalyzed isomerization of compound 4 could lead to the allenic enamine 8 and thus provide an alternative route to compound 6 . However, when compound 4 in dibutylamine

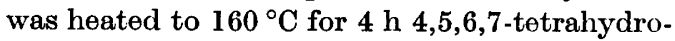
2-methylindol-4-one (11) was isolated as the sole product in $75 \%$ yield. This compound has previously been prepared in $21.5 \%$ yield only by heating compound 4 in ethanol with copper(I) chloride as a catalyst. ${ }^{5}$ In our reaction dibutylamine probably abstracts the relatively acidic amine proton from compound
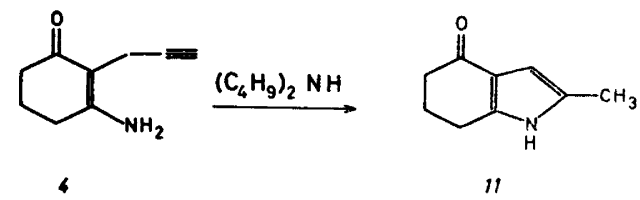

Scheme 2.

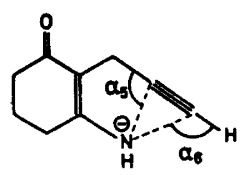

Fig. 1.

4; subsequent reaction of the amide anion with the acetylenic bond explains the formation of the observed indole derivative 11 .

According to the rules for ring closure put forward by Baldwin ${ }^{6}$ formation of both fiveand six-membered rings is favoured provided the angles $\alpha_{5}$ and $\alpha_{6}$ between the digonal carbon atoms and the approaching nucleophile are the same in both cases and preferably close to $120^{\circ}$ (see Fig. 1).

Molecular models show that an angle $\alpha_{5}$ closest to this value is obtained in a planar conformation, but in this conformation the angle $\alpha_{6}$ is quite similar in size; usually the Endo-Dig cyclization leading to a six-membered ring is preferred in contrast to the result in the present case.

When cyclohexenylvinyl ketones react with primary amines formation of decahydroquinolin-4-ones takes place. ${ }^{7}$ Another possible synthetic route to fused dihydropyridines therefore could be as outlined in Scheme 3.

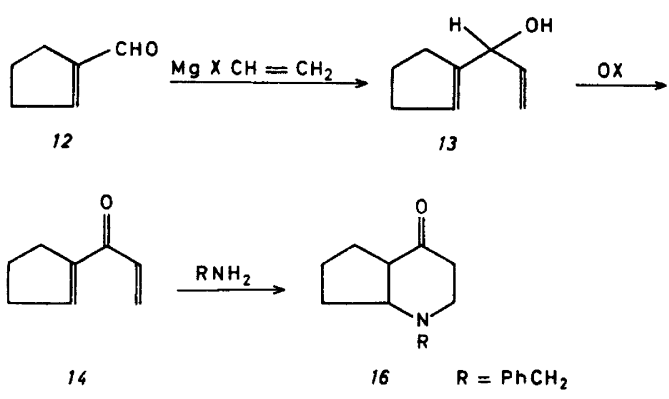

Scheme 3.

1.Cyclohexenecarbaldehyde can be prepared from 1-nitromethyl-1-cyclohexene by treatment with titanium(III) chloride. ${ }^{8}$ However, no 1-cyclopentenecarbaldehyde (12) could be detected from the reaction of I-nitromethyl-1cyclopentene under the same reaction conditions. Substance 12 therefore was prepared by a known method. ${ }^{9}$ It reacted with vinylmagnesium bromide to give $79 \%$ yield of $1-(1$ -

Acta Chem. Scand. B 32 (1978) No. 8 
cyclopentenyl)-2-propen $\lrcorner$-ol (13) which was easily oxidized by active manganese dioxide ${ }^{10}$ to 1-(1-cyclopentenyl)-2-propen-1-one (14) in $90 \%$ yield. The preparation of the 2,4-dinitrophenylhydrazone derivative (15) proceeded with addition of ethanol to the terminal double bond which took place either before or after hydrazone formation.

When the ketone 14 was heated with $25 \%$ aqueous ammonia a viscous mixture resulted from which no pure substance could be obtained. Heating at $90-100{ }^{\circ} \mathrm{C}$ with benzylamine, however, afforded a small amount of 1-benzyl-octahydro-1H-1-pyrindin-4-one (16). In its NMR spectrum the benzylic methylene protons appear as an $A B$ quartet due to the chirality of the molecule.

\section{EXPERIMENTAL}

Melting points were determined on a micro hot-stage. NMR spectra were recorded on Varian A-60 and HA 100 spectrometers with TMS as internal standard. IR spectra were obtained on a Perkin-Elmer 457 Grating Infrared Spectrophotometer and the mass spectra on an AEI/EC MS 902 instrument. Elemental analyses were performed by I. Beetz, West Germany.

3-(2-Propynylamino)-2-cyclopenten-1-one (1). A mixture of propargylamine hydrochloride (5.3 $\mathrm{g}, 50 \mathrm{mmol})$ in water $(5 \mathrm{ml})$, sodium hydroxide $(2.0 \mathrm{~g}, 50 \mathrm{mmol})$ in water $(2 \mathrm{ml})$ and cyclopentane-1,3-dione $(4.0 \mathrm{~g}, 40 \mathrm{mmol})$ in benzene $(50 \mathrm{ml})$ was refluxed with a water separator for $6 \mathrm{~h}$. The reaction mixture was decanted, cooled, and benzene removed at low pressure to give $4.1 \mathrm{~g}(76 \%)$ of compound 1 as pale yellow needles, m.p. $125-127^{\circ} \mathrm{C}$ (from chloroform and cyclohexane). Anal. $\mathrm{C}_{8} \mathrm{H}_{9} \mathrm{NO}: \mathrm{C}, \mathrm{H}$. MS $[m / e$ (\% rel. int.)]: $135(29.9, \mathrm{M}), 107(47.0)$, 106 (100), 79 (23.8), 78 (21.7), 68 (41.6), 53 (24.0), 52 (35.8), 39 (51.3). ${ }^{1} \mathrm{H} ~ \mathrm{NMR}\left(\mathrm{CDCl}_{3}\right)$ : $\delta 2.45$ ( $2 \mathrm{H}, \mathrm{t}, J 2.3 \mathrm{~Hz}$ ), 2.45 ( $2 \mathrm{H}$, complex), $\sim 2.75$ ( $2 \mathrm{H}$, complex), 3.97 ( $2 \mathrm{H}, \mathrm{dd}, J 2.3$ and $5.5 \mathrm{~Hz}), 5.15(1 \mathrm{H}, \mathrm{s}), 7.65-7.15(1 \mathrm{H}$, broad). IR (KBr): 3220 (s), 3190 (s), 3040 (s), $2910(\mathrm{~m}), 2125(\mathrm{~m}), 1648(\mathrm{~s}), 1575(\mathrm{~s}$, broad $)$, 1440 (s), 1281 (s), 1208 (s) $\mathrm{cm}^{-1}$.

3-(2-Propynylamino)-2-cyclohexen-1-one (2). To propargylamine hydrochloride (1.0 g, 10 $\mathrm{mmol})$ in hot ethanol $(10 \mathrm{ml})$ was added sodium hydroxide $(0.4 \mathrm{~g}, 10 \mathrm{mmol})$ in water $(1 \mathrm{ml})$. After cooling the precipitate was filtered off and cyclohexane-1,3-dione (1.1 g, $10 \mathrm{mmol})$ was added with stirring until completely dis. solved. After $1 \mathrm{~h}$ at room temperature the ethanol was removed to give $1.0 \mathrm{~g}(74 \%)$ of compound 2 as pale yellow crystals, m.p. $142.5-143.5^{\circ} \mathrm{C}$ (from ethyl acetate and ben- zene). Anal. $\mathrm{C}_{9} \mathrm{H}_{11} \mathrm{NO}: \mathrm{C}, \mathrm{H}$. MS [m/e (\% rel. int.)]: $149(39.1, \mathrm{M}), 120(44.8), 93(100), 66$ (24.6), 42 (31.6), 41 (24.9), 39 (51.4). ${ }^{1} \mathrm{H}$ NMR $\left(\mathrm{CDCl}_{3}\right): \delta \sim 2.30(7 \mathrm{H}$, complex), $3.92(2 \mathrm{H}$, dd, $J 2.2$ and $5.5 \mathrm{~Hz}$ ), $5.22(1 \mathrm{H}, \mathrm{s}), 6.34$ ( $\mathrm{I} \mathrm{H}$, broad s). IR (KBr): 3225 (s), 3040 (s), 2110 (w) $\mathrm{cm}^{-1}$.

3-(2-Propynylamino)indenone (3). To propargylamine hydrochloride $(1.0 \mathrm{~g}, 10 \mathrm{mmol})$ in hot ethanol $(10 \mathrm{ml})$ was added sodium hydroxide $(0.4 \mathrm{~g}, 10 \mathrm{mmol})$ in water $(1 \mathrm{ml})$. After cooling the precipitate was filtered off and indane-1,3-dione $(1.4 \mathrm{~g}, 10 \mathrm{mmol})$ was added to the solution. The mixture was heated at $80^{\circ} \mathrm{C}$ for $3 \mathrm{~h}$ before the solvent was removed to give $0.9 \mathrm{~g}(49 \%)$ of compound 3 as dark yellow needles, m.p. $170-172{ }^{\circ} \mathrm{C}$ (from toluene). Anal. $\mathrm{C}_{12} \mathrm{H}_{9} \mathrm{ON}: \mathrm{C}, \mathrm{H}$. MS [m/e ( $\%$ rel. int.)]: $183(29.3, \mathrm{M}), 182(100), 181$ (36.1), 155 (23.3), $154(29.1), 127(20.0), 102(20.1)$, 76 (20.3). ${ }^{1} \mathrm{H}$ NMR (acetone- $d_{B}$ ): 2.79 (1 H, t, $J 3 \mathrm{~Hz}), 4.20(2 \mathrm{H}, \mathrm{d}, J 3 \mathrm{~Hz}), 4.94(1 \mathrm{H}, \mathrm{s})$, $7.28-7.60$ (4 H, complex). IR (KBr): 3220 (s), $2100(\mathrm{w}), 1650(\mathrm{~m}), 1570$ (s) $\mathrm{cm}^{-1}$.

3-Amino-2-(2-propynyl)-2-cyclohexen-1-one (4). A mixture of 3-amino-2-cyclohexen-1-one ${ }^{11}$ (6.0 g, $50 \mathrm{mmol})$, sodium bicarbonate $(4.2 \mathrm{~g}, 50$ mmol) and propargyl bromide $(6.0 \mathrm{~g}, 50 \mathrm{mmol})$ in abs. ethanol $(100 \mathrm{ml})$ was refluxed for $24 \mathrm{~h}$. The solvent was removed and the resulting solid chromatographed on a column of silica gel with chloroform as eluent to give $4.4 \mathrm{~g}(59 \%)$ of compound 4 m.p. $104-106^{\circ} \mathrm{C}$ (from benzene).

6,7-Dihydro-1-pyrindin-5-one (5). Compound $1(0.4 \mathrm{~g}, 3 \mathrm{mmol})$ was heated to $195^{\circ} \mathrm{C}$ in nitrobenzene $(25 \mathrm{ml})$ for $1.5 \mathrm{~h}$. After cooling the mixture was extracted with $2 \mathrm{~N} H C l(50 \mathrm{ml})$ and the extract washed with ether $(50 \mathrm{ml} \times 3)$. After cautious neutralization with $50 \% \mathrm{NaOH}$ to $\mathrm{pH} \mathrm{10-11} \mathrm{the} \mathrm{water} \mathrm{layer} \mathrm{was} \mathrm{extracted}$ with ether $(50 \mathrm{ml} \times 3)$ and the ether removed to give $0.30 \mathrm{~g}(68 \%)$ of compound 5 , b.p. $125^{\circ} \mathrm{C} / 9 \mathrm{mmHg}$, m.p. $64-66^{\circ} \mathrm{C}$ (lit:11 b.p. $130{ }^{\circ} \mathrm{C} / 12 \mathrm{mmHg}$, m.p. $\left.62-64^{\circ} \mathrm{C}\right)$. Repeating experiments sometimes gave lower yield due to polymerization.

5,6,7,8-Tetrahydroquinolin-5-one (6). The procedure was as described above using compound $2(1.5 \mathrm{~g}, 3 \mathrm{mmol})$ to give $0.8 \mathrm{~g}(50 \%)$ of compound 6 , b.p. $54{ }^{\circ} \mathrm{C} / 0.04 \mathrm{mmHg}, n_{\mathrm{D}}^{20} 1.5630$, (lit:12 $116-117^{\circ} \mathrm{C} / 6 \mathrm{mmHg}, n_{\mathrm{D}}{ }^{20} 1.5643$ ).

5H-Indeno[1.2-b]pyridin-5-one (7). The procedure was as described above using compound $3(0.5 \mathrm{~g}, 3 \mathrm{mmol})$ to give $0.2 \mathrm{~g}(40 \%)$ of the product $\%$, m.p. $139-14.0^{\circ} \mathrm{C}$ (from othanol), (lit: ${ }^{13}$ m.p. $139.5-141.5^{\circ} \mathrm{C}$ ). The IR spectrum was consistent with that previously reported.13 4,5,6,7-Tetrahydro-2-methylindol-4-one (11). Compound $4(0.2 \mathrm{~g}, 1.3 \mathrm{mmol})$ was heated to $170{ }^{\circ} \mathrm{C}$ in dibutylamine $(25 \mathrm{ml})$ for $4 \mathrm{~h}$. The solvent was removed to give $0.15 \mathrm{~g}(75 \%)$ of compound 11 as white crystals, m.p. 207-208 ${ }^{\circ} \mathrm{C}$ (from benzene), (lit: ${ }^{5}$ m.p. $210-211^{\circ} \mathrm{C}$ ).

1-(1-Cyclopentenyl)-2-propen-1-ol (13). To a slurry of magnesium $(27.0 \mathrm{~g}, 1.1 \mathrm{~mol})$ and a

Acta Chem. Scand. B 32 (1978) No. 8 
crystal of iodine in tetrahydrofuran $(500 \mathrm{ml})$ under nitrogen with stirring and a Stoke condenser was added vinylbromide (160 g, 1.5 $\mathrm{mol})$ in dry tetrahydrofuran $(100 \mathrm{ml})$ during $3 \mathrm{~h}$ while the temperature in the mixture was kept at $45-50^{\circ} \mathrm{C}$. After heating for $1 \mathrm{~h}$ at $80^{\circ} \mathrm{C}$ the mixture was cooled to room temperature and 1-cyclopentenecarbaldehyde ${ }^{\circ}$ (12) $(21.0 \mathrm{~g}$, $0.2 \mathrm{~mol}$ ) was slowly added with some cooling. After $1 \mathrm{~h}$ the reaction mixture was hydrolyzed with saturated ammonium chloride solution. The layers were separated and the aqueous layer extracted 3 times with chloroform. The combined organic layers were dried, the solvent evaporated and the residue distilled to give $21.5 \mathrm{~g}(79 \%)$ of compound 13, b.p. $39^{\circ} \mathrm{C} /$ $0.02 \mathrm{mmHg}, n_{\mathrm{D}^{22}} 1.4848$ (lit: ${ }^{14}$ b.p. $43^{\circ} \mathrm{C} / 0.5$ $\left.\mathrm{mmHg}, n_{\mathrm{D}}{ }^{22} 1.4890\right)$.

1-(1-Cyclopentenyl)-2-propen-1-one (14). Compound $13(21.5 \mathrm{~g}, 173 \mathrm{mmol})$ and active manganese dioxide ${ }^{10}(400 \mathrm{~g})$ were stirred in pentane $(300 \mathrm{ml})$ for $30 \mathrm{~min}$, filtered and the solvent removed. The residue was distilled to give $19.0 \mathrm{~g}(90 \%)$ of compound 14 , b.p. $34-38$ ${ }^{\circ} \mathrm{C} / 0.04 \mathrm{mmHg}$. MS [m/e (\% rel. int.)]: 122 (62.5, M), 95 (100), 79 (30), 67 (86), 66 (19), $65(22) .{ }^{1} \mathrm{H}$ NMR $\left(\mathrm{CDCl}_{3}\right): 1.93(2 \mathrm{H}, \mathrm{qw}, J 7 \mathrm{~Hz})$, 2.63 (4 H, t, $J 7 \mathrm{~Hz}$ ), 5.68 (1 H, dd, $J 2.3$ and $10.0 \mathrm{~Hz}$ ), 6.25 ( $\mathrm{H}$, dd, $J 2.3$ and $17.0 \mathrm{~Hz}$ ), 6.81 (1 H, t, $J 1.5 \mathrm{~Hz}$ ), 6.95 ( $1 \mathrm{H}, \mathrm{dd}, J 10.0$ and $17.0 \mathrm{~Hz}$ ). IR (film): 3508 (m), 1665 (s), 1658 (s), $1614(\mathrm{~s}), 1608(\mathrm{~m}) \mathrm{cm}^{-1}$.

1-Benzyl-octahydro-1H-1-pyrindin-4-one (16). A mixture of benzylamine $(2.1 \mathrm{~g}, 20 \mathrm{mmol})$ and the ketone $12(2.5 \mathrm{~g}, 20 \mathrm{mmol})$ was kept at $90-100^{\circ} \mathrm{C}$ for $1 \mathrm{~h}$ and then distilled through a $2 \mathrm{~cm}$ column, b.p. $135^{\circ} \mathrm{C} / 0.01 \mathrm{mmHg}$. The destillate was dissolved in $2 \mathrm{~N} \mathrm{HCl}(5 \mathrm{ml})$ and washed with chloroform; the solution was made basic with $\mathrm{NH}_{3}$ and extracted with chloroform. Repetition of this purification procedure gave $0.3 \mathrm{~g}(13 \%)$ of compound 16 . MS $[\mathrm{m} / \mathrm{e}(\% \mathrm{rel}$. int)]: 229 (25.0, M), 200 (61.4), 91 (100), 65 (10.9). Mol. wt., obs. 229.1468, calc. for $\mathrm{C}_{15} \mathrm{H}_{19} \mathrm{NO} 229.1466$. ${ }^{1} \mathrm{H}$ NMR $\left(\mathrm{CDCl}_{3}\right): \delta 1.50-$ 3.34 (12 H, complex), $3.34(1 \mathrm{H})$ and 3.92 (1 H) $(A B$ quartet, $J 13.8 \mathrm{~Hz}), 7.30$ (4 H, complex). IR (film): 3030 (m), 2950 (s), 2872 (m), 2800 (s), 1715 (s), 1455 (s), 1350 (s), 740 (s), 698 (s) $\mathrm{cm}^{-1}$.

\section{REFERENCES}

1. Wolf, V. and Strauss, K. Justus Liebigs Ann. Chem. 713 (1968) 65.

2. Scheurer, H., Zsindely, J. and Schmid, H. Helv. Chim. Acta 56 (1973) 478.

3. Easton, N. R. and Cassady, D. R. J. Org. Chem. 27 (1962) 4713.

4. Easton, N. R. and Hennion, G. F. U.S. Pat. 3,331,846 (Cl 260-280), July 18, 1967, Appl. Febr. 18, 1966; Chem. Abstr. 67 (1967) 99627c.
5. Schulte, K. E., Reisch, J. and Lang, $H$. Chem. Ber. 96 (1963) 1470.

6. Baldwin, J. E. Chem. Commun. (1976) 734.

7. Vartanyan, S. A. and Chukhadzhyan, G. A. Izv. Akad. Nauk Arm. SSR, Khim. Nauki 12 (1959) 179; Chem. Abstr. 54 (1961) $7707 \mathrm{~b}$.

8. Ho, T.-L. and Wong, C. M. Synthesis (1974) 196.

9. English, J. and Barber, G. W. J. Am. Chem. Soc. 71 (1949) 3310.

10. Carpino, L. A. J. Org. Chem. 35 (1970) 3971.

11. Ruangsiyanand, C., Rimek, H..J. and Zymalkowski, F. Chem. Ber. 103 (1970) 2403.

12. Zymalkowski, F. and Rimek, H..J. Arch. Pharm. (Weinheim) 294 (1961) 759.

13. Abramovitch, R. A., Choo Seng, G. and Notation, A. D. Can. J. Chem. 38 (1960) 761 .

14. Braude, E. A. and Forbes, W. F. J. Chem. Soc. (1951) 1755 .

Received April 28, 1978. 